Check for updates

Cite this: RSC Adv., 2017, 7, 22178

\title{
EGF-targeting lipodisks for specific delivery of poorly water-soluble anticancer agents to tumour cells $\dagger$
}

\begin{abstract}
Sara Ahlgren, (D) a Amelie Fondell, ${ }^{a}$ Lars Gedda ${ }^{b c}$ and Katarina Edwards (D) *a
Concerns regarding poor aqueous solubility, high toxicity and lack of specificity impede the translation of many hydrophobic anticancer agents into safe and effective anticancer drugs. The application of colloidal drug delivery systems, and in particular the use of lipid-based nanocarriers, has been identified as a promising means to overcome these issues. PEG-stabilized lipid nanodisks (lipodisks) have lately emerged as a novel type of biocompatible, nontoxic and adaptable drug nanocarrier. In this study we have explored the potential of lipodisks as a platform for formulation and tumour targeted delivery of hydrophobic anticancer agents. Using curcumin as a model compound, we show that lipodisks can be loaded with substantial amounts of hydrophobic drugs (curcumin/lipid molar ratio 0.15). We demonstrate moreover that by deliberate choice of preparation protocols the lipodisks can be provided with relevant amounts of targeting proteins, such as epidermal growth factor (EGF). Data from in vitro cell studies verify that such EGF-decorated curcumin-loaded lipodisks are capable of EGF-receptor specific targeting of human A-431 tumour cells, and strongly suggest that the interaction between the lipodisks and the tumour cells results in receptor-mediated internalization of the disks and their cargo.
\end{abstract}

Received 10th April 2017

Accepted 12th April 2017

DOI: $10.1039 / \mathrm{c} 7 \mathrm{ra0} 4059 \mathrm{~h}$

rsc.li/rsc-advances

promising and frequently used agents are ligands and antibody-

\section{Introduction}

The number of biomolecules and synthetic compounds with documented antitumour activity is steadily increasing. In many cases, however, issues concerning poor aqueous solubility and/ or the risk of severe side effects on healthy cells and organs hamper further development of the compounds into safe and effective anticancer drugs. The use of well-designed drug nanocarriers may offer a solution to both these problems. Thus, apart from increasing the aqueous solubility and circulation half-life of the drug, encapsulation of the drug in nanocarriers may favourably alter the biodistribution and lead to increased tumour levels. The latter is partly due to the so-called enhanced permeability and retention (EPR) effect, ${ }^{1,2}$ which allows nanocarriers of appropriate size $(10-500 \mathrm{~nm})$ to infiltrate the tumour endothelium and passively accumulate in tumour tissue. ${ }^{3}$ In addition, active targeting of tumour cells can be achieved by linking targeting agents, such as protein ligands, peptides, or antibodies, to the surface of the nanocarriers. ${ }^{4}$ Among the most

${ }^{a}$ Department of Chemistry - BMC, Uppsala University, Box 579, SE-751 23, Sweden. E-mail: katarina.edwards@kemi.uu.se; Tel: +46184713668

${ }^{b}$ Department of Immunology, Genetics and Pathology, Uppsala University, SE-751 85, Sweden

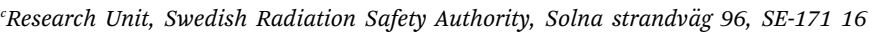
Stockholm, Sweden

$\dagger$ Electronic supplementary information (ESI) available. See DOI: 10.1039/c7ra04059h fragments that bind with high affinity to upregulated/overexpressed cell-surface receptors on the tumour cells. Importantly, by choosing receptors that mediate endocytosis, such as the folate and transferrin receptors, or members of the EGFreceptor family, it is possible to design nanocarriers capable of mediating selective intracellular drug delivery. Exploitation of the endocytotic pathways enables moreover internalization of the drug in its nanocarrier-encapsulated form, which can be advantageous in order to bypass drug efflux transporters and help overcome problems with multidrug resistance. ${ }^{5}$

A broad range of nanocarriers, including, lipid-, polymer-, and metal-based nanoparticles, have been suggested and tested for the formulation and delivery of poorly water-soluble anticancer drugs. ${ }^{6,7}$ Since most of the drugs are lipophilic, lipidbased carriers constitute a natural first choice, which is further justified by the excellent biocompatibility and low toxicity of this class of carriers. ${ }^{8}$ The perhaps best known lipid nanocarriers are the liposomes, which, due to their hollow structure and large aqueous core, have been extensively used for formulation and delivery of water soluble anticancer agents. ${ }^{9}$ Certain lipophilic/hydrophobic compounds, such as the antifungal drug amphotericin $\mathrm{B}^{10}$ and the chemotherapeutic agent paclitaxel, ${ }^{11}$ have also been successfully formulated in liposomes. The drug-loading capacity of the lipid membrane is limited, however, and careful optimizations are as a rule needed to ensure that the incorporation of the drug does not cause detrimental changes to the integrity and stability of the 
liposomes. Further, the hollow liposome structure inevitably leads to a greater than necessary size of the nanocarrier. The comparably large particle size (typically about $100 \mathrm{~nm}$ in case of liposomes adapted for systemic administration ${ }^{\mathbf{1 2}}$ ) may in turn lead to a suboptimal biodistribution of the nanocarriers, as well as hamper their ability to penetrate deep into tumour tissue. Growing evidence suggest moreover that the shape of the nanocarrier can have an important influence on both the pharmacokinetics and the tumour cell uptake. Noteworthy, recent studies indicate that a non-spherical particle shape may favourably affect the blood circulation time and biodistribution. ${ }^{13}$ The purpose of the present work was to explore the potential of a novel type of non-spherical lipid-based nanocarriers, known as lipodisks, for formulation and targeted delivery lipophilic anticancer drugs.

Lipodisks are nanosized lipid bilayers stabilized into a discoidal shape by edge-active PEG-lipids (Fig. 1). Since their discovery almost two decades ago, ${ }^{\mathbf{1 4}}$ the lipodisks have proven their utility as adaptable and versatile biomimetic membranes. ${ }^{\mathbf{1 5 - 1 7}}$ During the last couple of years these non-toxic, biocompatible structures have also received increasing attention as novel drug carriers.

Examples of the latter application include the use of lipodisks for successful formulation and administration of doxorubicin, ${ }^{18}$ as well as of amphiphilic peptides with documented antitumour and antimicrobial activity. ${ }^{19,20}$ In addition to their non-toxic nature, lipodisks have several other properties that render them well suited as vehicles for drug delivery. Thus, the disks display excellent temperature, concentration and longterm stability, and their composition and size can easily be changed and adapted. Details about the preparation and physico-chemical properties of lipodisks can be found in, e.g., the recent study by Zetterberg et al., ${ }^{21}$ and references therein. Importantly, the densely PEGylated rim, and plausibly also the non-spherical shape, help promote long blood circulation times of the lipodisks. In line with this, results from in vivo animal studies indicate plasma half-lives superior to those of, e.g., PEGylated liposomes. ${ }^{18}$ Biodistribution studies performed in mice models show, moreover, that lipodisks, similar to liposomes, spontaneously accumulate in subcutaneously grown tumours. ${ }^{18,20}$ Studies in glioma tumour-bearing mice suggest in addition that the tumour accumulation, as well as the therapeutic effect, of drug-loaded lipodisks can be improved by grafting cyclic RGD peptides to their surface. ${ }^{20}$ So far, however, no evidence has been presented on the successful construction of lipodisks capable of specific tumour cell targeting and true intracellular drug delivery.

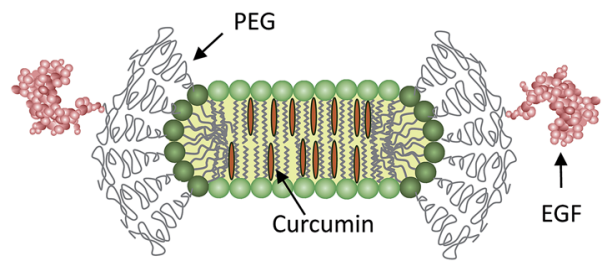

Fig. 1 Schematic illustration showing a curcumin containing targeting lipodisk in cross section.
In the present study we investigate the possibilities to specifically deliver a poorly soluble model drug, curcumin, to tumour cells by use of EGF-targeting lipodisks.

\section{Experimental}

\section{Materials}

Murine Epidermal Growth Factor (EGF) was obtained from Millipore (Molsheim, France). NHS-PEG 3400 -DSPE was purchased from Shearwater polymers (Huntsville, AL, USA). Buffers such as 0.1 M Phosphate buffered saline (PBS, pH 7.5) and $20 \mathrm{mM}$ Hepes buffered saline (HBS, pH 7.4) were prepared using common methods from chemicals supplied by Merck (Darmstadt, Germany) or Sigma Aldrich (St. Louis, MO, USA). High-quality Milli-Q water (resistance higher than $18 \mathrm{M} \Omega \mathrm{cm}^{-1}$ ) was used for preparing solutions. The lipid 1,2-dipalmitoyl-sn-glycero-3-phosphocholine (DPPC) was purchased from Avanti Polar Lipids (Alabaster, AL, USA). Cholesterol, octyl $\beta$-D-glucopyranoside (OG, phosphate free was used for productions analysed with phosphorous analysis), Dimethyl sulfoxide (DMSO) and Curcumin were all obtained from Sigma Aldrich (St. Louis, MO, USA). ${ }^{3} \mathrm{H}-$ Curcumin was bought from ARC (St. Louis, MO, USA). BioBeads $^{\text {TM }}$ SM-2 Resin were from Bio-Rad Laboratories (Richmond, CA, USA). Cells in the in vitro experiments were detached using trypsin-EDTA solution (0.25\% trypsin, 0.02\% EDTA in buffer, Biochrom AG, Berlin, Germany) or Accutase (Sigma Aldrich, St. Louis, MO, USA). The Sephadex G-25 columns (NAP-5 columns), Sephadex G-150, Sepharose CL-4B and Sephadex G-50 gels used for purification and detergent depletion were purchased from Amersham Biosciences, Uppsala, Sweden.

\section{Radiolabeling of EGF and conjugation of EGF to NHS-PEG 3400}

$25 \mu \mathrm{g}$ of EGF $\left(1 \mu \mathrm{g} \mu \mathrm{L}^{-1}\right.$ in PBS) was labelled with ${ }^{125} \mathrm{I}(20 \mathrm{MBq}$ for LigandTracer in vitro assay, $2 \mathrm{MBq}$ for all other assays) essentially as described by Bohl Kullberg et al. ${ }^{22}$ The separation on the NAP-5 column was eluted with PBS and the peak containing ${ }^{125}$ I-EGF were pooled (total volume $600 \mu \mathrm{L}$ ). Additional $175 \mu \mathrm{g}\left(1 \mu \mathrm{g} \mu \mathrm{l}^{-1}\right.$ in PBS) of EGF was added to the pooled ${ }^{125} \mathrm{I}$ EGF, gaining a total volume of $775 \mu \mathrm{L}(200 \mu \mathrm{g})$.

Conjugation of ${ }^{125}$ I-EGF to NHS-PEG 3400 -DSPE was performed as described earlier. ${ }^{23}$ The reaction mixture was incubated over night at room temperature. ${ }^{125}$ I-EGF-PEG $_{3400}$-DSPE was purified from ${ }^{125}$ I-EGF by gel filtration (Sephadex G-150) using HBS as elution buffer. As judged from gamma counter measurements (1480 WIZARD, Wallac Oy, Turku, Finland) of samples collected from the fractions representing the two separated peaks, the used protocol resulted in conjugation of EGF to $\sim 5 \%$ of the NHS$\mathrm{PEG}_{3400}$-DSPE lipids. The same protocol was used for conjugation of non-radiolabelled EGF to NHS-PEG 3400 -DSPE.

\section{Preparation of lipodisks}

Lipodisks were produced by means of probe sonication and detergent depletion using either size-exclusion chromatography or porous polystyrene beads (BioBeads). In all cases the total lipid amount in the starting material corresponded to $2 \mu \mathrm{mol}$. 
Probe sonication. DPPC, cholesterol, $\mathrm{PEG}_{2000}$-DSPE, and curcumin (molar ratio $2: 2: 1: 1$ ) were co-dissolved in chloroform. The solvent was removed under a gentle stream of nitrogen gas and the sample was thereafter further dried in vacuum for at least $15 \mathrm{~h}$. The dry lipid film was hydrated in 2 $\mathrm{mL}$ HBS at $60{ }^{\circ} \mathrm{C}$ for approximately $30 \mathrm{~min}$ with intermittent freezing in liquid nitrogen every $10 \mathrm{~min}$. The hydrated and freeze-thawed sample was thereafter sonicated for 10 minutes using a Soniprep 150 sonicator (MSE Scientific Instruments, London, England). During sonication the sample was kept in ice-cold water. Metal residues from the sonicator probe tip were removed by centrifuging the sample for $2 \mathrm{~min}$ at $268 g$.

Detergent depletion using size-exclusion chromatography (SEC). Lipodisks composed of DPPC, cholesterol, NHSPEG $_{3400}$-DSPE (molar ratio $2: 2: 1$ ) and curcumin were prepared by means of a two-vial procedure. DPPC, cholesterol, and curcumin were co-dissolved in chloroform. For preparation of ${ }^{3} \mathrm{H}$-curcumin-containing lipodisks, $1.85 \mathrm{MBq}$ of ${ }^{3} \mathrm{H}$ curcumin (in ethanol) was also added to the solution. The dissolved components were subsequently dried under a gentle stream of nitrogen gas and the vial left in vacuum for at least $15 \mathrm{~h}$. The film was thereafter rehydrated in $1 \mathrm{~mL} 40.7 \mathrm{mM}$ OG and HBS at $60{ }^{\circ} \mathrm{C}$ for about $30 \mathrm{~min}$ (moderate mixing every 5 min). In a separate vial, NHS-PEG ${ }_{3400}$-DSPE was incubated in the same way with $40.7 \mathrm{mM}$ OG and HBS (total volume of 1 $\mathrm{mL})$. The content of both vials were thereafter pooled, and the mixture (1:5 curcumin : lipid molar ratio) incubated for another $30 \mathrm{~min}$ at $60{ }^{\circ} \mathrm{C}$. The sample was allowed to cool to room temperature and then applied to a Sephadex G-50 column $(35 \times 1.9 \mathrm{~cm})$. HBS was used as mobile phase and a Gilson Pump Minipuls 2 (Gilson International, Den Haag, Netherlands) was used to control the flow rate to approximately $0.7 \mathrm{~mL} \mathrm{~min}^{-1}$. The lipodisks and the detergent were eluted from the column as two well separated fractions. A Dual Path Monitor UV-2 (Pharmacia Fine Chemicals, Uppsala, Sweden) was used to detect the fractions. The lipodisk fraction was collected manually and stored at $4{ }^{\circ} \mathrm{C}$ until further use.

Detergent depletion using BioBeads. Dispersions containing DPPC, cholesterol, NHS-PEG ${ }_{3400}$-DSPE (molar ratio $2: 2: 1$ ) or, when indicated DPPC, cholesterol, NHS-PEG 3400 -DSPE and curcumin (molar ratio $2: 2: 1: 1$ ), were prepared by means of the two-vial procedure as described above. In cases were ${ }^{3} \mathrm{H}$ DPPC was used, $2.2 \mathrm{MBq}$ of ${ }^{3} \mathrm{H}$-DPPC (toluene : etanol, $1: 1$ ) was added to the chloroform solution before evaporation of the solvent. In order to remove OG from the pooled aqueous dispersions the samples were incubated with approximately $0.3 \mathrm{~g}$ of degassed BioBeads (wet weight) for $2 \mathrm{~h}$ at room temperature under rotation. After incubation the supernatant, containing the lipodisks, was transferred to a fresh vial using a syringe with an injection needle. For curcumin containing lipodisks the solution was centrifuged at $9592 \mathrm{~g}$ for $15 \mathrm{~min}$ to remove unbound curcumin crystals and the supernatant containing the lipodisks transferred to a fresh vial.

EGF-targeting lipodisks. Targeting lipodisks were prepared by replacing $\sim 5 \%$ (see Conjugation section above) of the NHS-
PEG $_{3400}$-DSPE with EGF-NHS-PEG 3400 -DSPE or ${ }^{125}$ I-EGF-NHS$\mathrm{PEG}_{3400}$-DSPE in the production protocols based on SEC and BioBeads.

\section{Characterization of the lipodisks}

Cryogenic transmission electron microscopy. Cryogenic transmission electron microscopy (Cryo-TEM) was used to characterize the lipid samples and confirm lipodisk formation. Specimens were prepared by depositing a small drop $(\sim 1 \mu \mathrm{L})$ of the lipid sample on a copper grid covered with a holey polymer film. Thin liquid films $(10-500 \mathrm{~nm})$ were prepared by blotting the grid with a filter paper in a custom built climate chamber at $25{ }^{\circ} \mathrm{C}$ and close to $100 \%$ relative humidity ( $\left.\mathrm{RH}\right)$. The grid was then immediately plunged into liquid ethane held at a temperature just above its freezing point $\left(-183^{\circ} \mathrm{C}\right)$, resulting in vitrification of the liquid films. The specimens were kept at a temperature below $-165{ }^{\circ} \mathrm{C}$ and protected against atmospheric conditions both during transfer from the climate chamber to the microscope and throughout the entire sample examination. A detailed description of the technique has been presented by Almgren et al. ${ }^{24}$ TEM analysis was performed with a Zeiss TEM Libra 120 instrument (Carl Zeiss NTS, Germany) operated at $80 \mathrm{kV}$ in zero-loss bright-field mode. Digital images were recorded under low dose conditions with a TRS slow scan CCD camera system (TRS GmbH, Germany) and iTEM software (Olympus Soft Imaging Solutions GmbH, Germany). An underfocus of 1-3 $\mu \mathrm{m}$ was used in order to enhance the contrast.

Dynamic light scattering (DLS). The size distributions of the lipodisks in the preparations were analyzed using dynamic light scattering (DLS). The experimental setup consisted of a Uniphase He-Ne laser (Milpitas, CA) emitting vertically polarized light with a wavelength of $632.8 \mathrm{~nm}$ operating at $25 \mathrm{~mW}$. The scattered light was detected at $90^{\circ}$ scattering angle using a Perkin Elmer (Quebec, Canada) diode detector connected to an ALV-5000 multiple digital autocorrelator (ALV-laser, Vertriebsgesellschaft, Germany).

\section{Quantification of curcumin and lipid content}

The curcumin content in the lipodisks preparations was determined by means of absorbance and/or radioactivity measurements. In case of the former, a $2 \mathrm{mg} \mathrm{mL}^{-1}$ stock solution of curcumin was prepared in DMSO. A standard curve was then generated by serial dilution of the stock solution and used to determine the curcumin concentration in the lipodisk preparations. Aliquots of the preparations were transferred to DMSO followed by measurements using ultraviolet-visible (UVvis) absorbance spectroscopy (HP 8453, Agilent Technologies, Santa Clara CA, USA). Samples were scanned from 300 to $700 \mathrm{~nm}$. In cases where ${ }^{3} \mathrm{H}$-labelled curcumin was included in the preparations, the quantification was based on radioactivity measurements performed by use of a liquid scintillator counter (1214 RackBeta Excel, Perkin Elmer, Wellesley, MA, USA).

The total phospholipid content in the lipodisk preparations was determined from measurements of the phosphorous content in the samples. Phosphorus analysis was performed as described by Paraskova et al. with the modification that the 
digestion was performed solely by dry ashing at $550{ }^{\circ} \mathrm{C}$ for $4 \mathrm{~h}$ (other steps of the digestion were considered redundant). ${ }^{25}$ In case of lipodisk production by means of SEC, the recovered proportions of the DPPC and cholesterol components were determined from experiments in which ${ }^{3} \mathrm{H}$-DPPC and ${ }^{3} \mathrm{H}$ cholesterol, respectively, were included in the preparations. The radioactivity in aliquots of the original sample and the fractions collected after SEC were assessed by means of measurements using the scintillator counter specified above. Radioactivity measurements were in a similar way used to assess the final content, and recovered proportion, of cholesterol in lipodisks prepared by use of BioBeads.

\section{Cell culture}

A-431 cells (squamous cell carcinoma cell line, CLR 1555, ATCC, Rocksville, MD, USA), overexpressing the human epidermal growth factor receptor (EGFR) was cultured in Ham's F10 medium (Flow Irvine, UK) supplemented with 10\% fetal calf serum (Sigma, USA), $2 \mathrm{mM}$-glutamine and PEST (100 IU mL $\mathrm{mL}^{-1}$ penicillin, $100 \mu \mathrm{g} \mathrm{mL}^{-1}$ streptomycin), both from Biokrom, Berlin, Germany (further referred to as complete media in the text).

\section{In vitro cell studies}

Real-time analysis of binding and retention of curcumin containing targeting lipodisks (DPPC/cholesterol/curcumin $/{ }^{125} \mathrm{I}$ EGF-NHS-PEG 3400 -DSPE) on A-431 cells $\left(1 \times 10^{6}\right.$ cells per Petri dish (diameter $10 \mathrm{~cm}$ ), cultivated in $3 \mathrm{~mL}$ complete media with the Petri dishes inclined to allow cell growth only in the lower end of the Petri dish) was performed using a LigandTracer Gray instrument (Ridgeview Instruments, Uppsala, Sweden). The experiments were performed at $4{ }^{\circ} \mathrm{C}$ to avoid receptor internalization and possible rapid release of ${ }^{125} \mathrm{I}$ after cellular processing. The binding kinetics were studied during a two-step, three-fold increase of the concentration: 1 and $3 \mu \mathrm{M}$ with respect to total lipid concentration. The first concentration was run until a nonlinear, asymptotic increase in the signal was observed, approximately $5 \mathrm{~h}$, before the second concentration (3 $\mu \mathrm{M})$ was applied. After a further $17 \mathrm{~h}$ of incubation the incubation medium was removed and $7 \mathrm{~mL}$ complete cell medium was added to study the cellular retention of the lipodisks. In parallel, a blocking experiment was performed to study if the binding could be inhibited by the addition of high concentrations of EGF. In this case EGF was added to a total concentration of $100 \mathrm{nM} 30 \mathrm{~min}$ prior to the addition of the first concentration of curcumin containing targeting lipodisks. In all other aspects the experiment were performed as described above. To further evaluate the receptor specificity, a separate experiment was conducted in which an excess amount of free EGF was instead added subsequent to the incubation of the cells with the EGF-targeting lipodisks (see ESI $\dagger$ for details).

In vitro binding characteristics of curcumin containing EGFtargeting lipodisks ( ${ }^{3} \mathrm{H}$-DPPC/cholesterol/curcumin/EGF-NHS$\mathrm{PEG}_{3400}$-DSPE) and curcumin containing non-targeting lipodisks ( ${ }^{3} \mathrm{H}$-DPPC/cholesterol/curcumin/NHS-PEG $\left.{ }_{3400}-\mathrm{DSPE}\right)$ were studied on cultured A-431 cells. Two separate groups of cell dishes ( 3 dishes per time point; diameter, $3.5 \mathrm{~cm} ; \sim 3 \times 10^{5}$ cells per dish) were incubated with $3 \mu \mathrm{M}$ (total lipid concentration) targeting lipodisks in complete cell media. In one of these groups, the EGFRs were pre-saturated for 5 min with $100 \mathrm{nM}$ EGF. A third group of cell dishes (3 dishes per time point; diameter, $3.5 \mathrm{~cm} ; \sim 3 \times 10^{5}$ cells per dish) was incubated with 3 $\mu \mathrm{M}$ non-targeting disks in cell media. The total volume in all dishes was $1 \mathrm{~mL}$. Cells were incubated for $0.5,1$ or $3 \mathrm{~h}$ at $37^{\circ} \mathrm{C}$ before incubation medium was removed. The cells were washed three times with cold serum-free medium followed by treatment with $0.5 \mathrm{~mL}$ trypsin-EDTA solution for $10 \mathrm{~min}$ at $37^{\circ} \mathrm{C}$. When cells were detached, $0.5 \mathrm{~mL}$ cell media was added to each dish, and the cells were re-suspended and collected. The radioactivity associated with the cells and medium, respectively, was measured in a liquid scintillator counter (1214 RackBeta Excel, Perkin Elmer, Wellesley, MA, USA).

To study cellular internalization, EGF-targeting lipodisks $\left({ }^{3} \mathrm{H}\right.$-DPPC/cholesterol/EGF-NHS-PEG ${ }_{3400}$-DSPE) and nontargeting lipodisks $\left({ }^{3} \mathrm{H}-\mathrm{DPPC} / \mathrm{cholesterol} / \mathrm{NHS}^{-P_{E G}}{ }_{3400}-\mathrm{DSPE}\right)$ where each incubated with A-431 cells in two groups of cell dishes ( 3 dishes per group; diameter, $3.5 \mathrm{~cm} ; 3 \times 10^{5}$ cells per dish) at $3 \mu \mathrm{M}$ (volume $1 \mathrm{~mL}$ ) in cell media for $3 \mathrm{~h}$. In case of both types of lipodisks, one group of cell dishes was incubated at $37{ }^{\circ} \mathrm{C}$ and the other group was incubated at $4{ }^{\circ} \mathrm{C}$ to prevent receptor internalization. All steps beyond this were performed on ice for both groups. After the incubation, the incubation media was collected and the cell dishes were washed three times with ice-cold serum-free media. To remove membranebound lipodisks, $0.5 \mathrm{~mL}$ of $0.1 \mathrm{M}$ glycine- $\mathrm{HCl}$ solution $(\mathrm{pH}$ 2.5) was added to each dish and cells were incubated for $5 \mathrm{~min}$ on ice. The acid solution was collected and cells where washed with additional $0.5 \mathrm{~mL}$ acid solution. The radioactivity (measured by liquid scintillation counting) in the acid wash fraction was considered derived from membrane-bound lipodisks. To lyse cells, $0.5 \mathrm{~mL}$ of $1 \mathrm{M} \mathrm{NaOH}$ solution was added to cell dishes and cells were incubated for at least $30 \mathrm{~min}$ at $37^{\circ} \mathrm{C}$. The $\mathrm{NaOH}$ solution was collected and the dishes washed with another $0.5 \mathrm{~mL}$ of $\mathrm{NaOH}$. The radioactivity measured in the alkaline fractions was considered derived from internalized lipodisks.

Cellular uptake of curcumin was assessed in studies using lipodisks loaded with ${ }^{3} \mathrm{H}$-labelled curcumin. A-431 cells were grown as described above and thereafter detached using Accutase ${ }^{\circledR}$ for $10-15 \mathrm{~min}$ in room temperature. After suspension of the cells, $3.5 \times 10^{6}$ cells were transferred to two groups $(n=3)$ of $20 \mathrm{~cm}^{3}$ siliconized glass flasks. The volume was adjusted to $10 \mathrm{~mL}$ and for one group of cells EGF-targeting lipodisks (DPPC/cholesterol ${ }^{3} \mathrm{H}$-curcumin/EGF-NHS-PEG ${ }_{3400^{-}}$ DSPE) were added to a final lipodisk concentration of $3 \mu \mathrm{M}$. The other group of cells was incubated with $3 \mu \mathrm{M}$ of non-targeting lipodisks (DPPC/cholesterol ${ }^{3} \mathrm{H}$-curcumin/NHS-PEG ${ }_{3400}$-DSPE). Flasks were kept at constant roll to ensure circulation of the cells during incubation in $37^{\circ} \mathrm{C}$. After $1 \mathrm{~h}$ aliquots of $2 \mathrm{~mL}$ were taken from the flasks and centrifuged for $5 \mathrm{~min}$ at $225 \mathrm{~g}$. The supernatant was removed and $2 \mathrm{~mL}$ serum-free medium was added. Cells were re-suspended and centrifuged another $5 \mathrm{~min}$. The washing procedure was repeated once, where after the cells 
were re-suspended in $1 \mathrm{~mL}$ serum free medium. Finally, the radioactivity in the cell suspension was measured by liquid scintillation counting.

\section{Statistics}

Data obtained in the cell studies were analyzed by unpaired, two-tailed $t$-test using GraphPad Prism (version 4.00 for Windows GraphPad Software, San Diego, California, USA) in order to determine any significant differences $(P<0.05)$.

\section{Results and discussion}

\section{Formulation of curcumin in lipodisks}

The aim of the present study was to investigate the potential of targeting-lipodisks for specific deliver of poorly water-soluble anticancer agents into tumour cells. In the selection of a suitable model drug, our choice fell on the diphenolic compound curcumin (Fig. 2). Apart from exhibiting activity against a broad range of conditions, including inflammatory and infectious deceases, neurological disorders, diabetes and several cardiovascular conditions, curcumin has been shown to inhibit proliferation and growth of a variety of tumour cell lines..$^{26,27}$ The antitumour activity<smiles>COc1cc(/C=C/C(=O)/C=C(O)/C=C/c2ccc(O)c(OC)c2)ccc1O</smiles>

Fig. 2 Structural formula of curcumin. of curcumin has been extensively investigated during the last decade and results from preclinical and clinical studies point towards curcumin as a promising antitumour agent. ${ }^{28}$ Curcumin's extremely low aqueous solubility, together with its susceptibility to degradation and rapid systemic elimination, severely limits, however, its use as therapeutic agent. Formulation of curcumin in nanocarriers has been identified as one of the most promising strategies to overcome these issues. ${ }^{26,27,29}$

We investigated and compared three different methods for the production of curcumin-loaded lipodisks. The preparation protocols, which are described in detail in the Methods section, were based on probe sonication and detergent depletion using either size-exclusion chromatography (SEC) or BioBeads. In all cases cryo-TEM analysis confirmed that the final lipid dispersion were dominated by nanosized discoidal particles, i.e., lipodisks. As seen in Fig. 3a and c, a small population of liposomes was found in coexistence with the lipodisks. The micrographs shown in Fig. 3 reveal moreover that the method of preparation affects the size of the disks. Thus, the disks prepared by SEC were on average smaller than those produced by sonication and by BioBeads-assisted detergent depletion. The small size of the lipodisks produced by SEC, which is in line with previous findings on the influence of lipodisk preparation path, ${ }^{30}$ was further confirmed by DLS measurements (see ESI Fig. S1†). Thus, as shown in Table 1, the apparent hydrodynamic radius $\left(R_{\mathrm{h}}\right)$ was found to be $\sim 15$ and $\sim 13 \mathrm{~nm}$ for lipodisks prepared by means of sonication and BioBeads, respectively, whereas lipodisks prepared by SEC had apparent hydrodynamic radii corresponding to $\sim 7 \mathrm{~nm}$.

Apart from affecting the lipodisk size, the choice of preparation protocol was found to influence on the curcumin/lipid
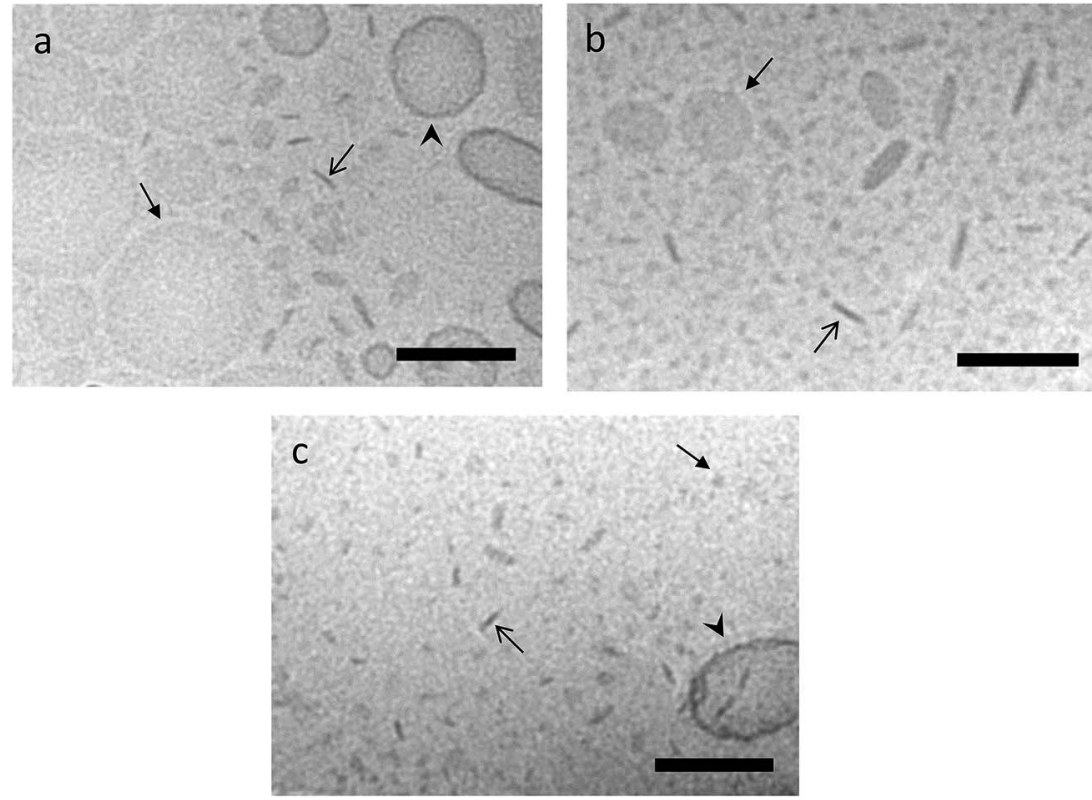

Fig. 3 Cryo-TEM analysis of curcumin containing targeting lipodisks (DPPC/cholesterol/curcumin/EGF-NHS-PEG $3400-D S P E$ ) produced by sonication (a) or detergent depletion using BioBeads (b) and SEC (c). The closed and open arrows point to lipodisks observed face-on and edgeon, respectively. Note that many lipodisks are seen in orientations that fall in between these two extremes. Arrowheads in (a) and (c) point to liposomes. Scale bar represents $100 \mathrm{~nm}$. 
Table 1 Curcumin/lipid molar ratios and apparent hydrodynamic radii $\left(R_{h}\right.$, calculated from unweighted size distributions) of lipodisks prepared by different production protocols

\begin{tabular}{lll}
\hline Production method & Curcumin/lipid molar ratio $^{a}$ & $R_{\mathrm{h}}(\mathrm{nm})$ \\
\hline Sonication & 0.15 & $\sim 15^{b}$ \\
SEC & 0.13 & $\sim 7$ \\
BioBead & 0.015 & $\sim 13$
\end{tabular}

${ }^{a}$ See ESI Table S1 and S2 for details about the phospholipid and cholesterol content in the lipodisks. ${ }^{b}$ Due to the monomodal appearance of the size distribution calculated from unweighted data (see ESI Fig. S1), $R_{\mathrm{h}}$ was calculated from the number weighted data.

ratio in the final lipodisk formulations. As reported in Table 1, the highest curcumin/lipid molar ratio, 0.15, was obtained when employing the protocol based on sonication. It is noteworthy that the loading capacity determined for sonicated samples is similar to that reported by Ghosh et al. for sonication-based formulation of curcumin in nanodisks stabilized by an apolipoprotein scaffold. ${ }^{31}$ Preparation using detergent depletion by means of SEC resulted in a curcumin/lipid molar ratio corresponding to 0.13. The method based on BioBeads returned the lowest ratio, 0.015. It may be noted that this method also resulted in lipodisks with slightly lower cholesterol content (see ESI, Table S2†).

\section{Targeting lipodisks}

An important objective of this study was to identify efficient formulation strategies by which drug-loaded lipodisks can be provided with sufficient quantities of relevant targeting agents. In the present work we chose to target the epidermal growth factor receptor (EGFR), also known as ErbB-1 and HER1 in humans. EGFR is over-expressed in several human cancers ${ }^{32}$ and promising results have been obtained in preclinical studies using nanocarriers, and in particular liposomes, targeted against this receptor. ${ }^{33,34}$ In a recent study we reported results pointing towards the possibility of using the natural ligand, epidermal growth factor (EGF), as targeting agent for lipodisks. $^{21}$ In the present work we have further explored this approach.

In order to provide the lipodisks with EGF, the protein was first conjugated to NHS-PEG 3400 -DSPE. Investigations based on the use of radiolabelled EGF $\left({ }^{125} \mathrm{I}\right.$-EGF) confirmed that the coupling protocol used (see Methods section) resulted in a $1: 22$ ratio of EGF-NHS-PEG ${ }_{3400}$-DSPE to NHS-PEG $_{3400}-$ DSPE. The EGF-conjugated PEG-lipids were subsequently included in the starting material used for lipodisk production by means of detergent depletion. This route of preparation was chosen over sonication, since EGF, similar to many ligands, peptides and antibodies employed as targeting agents, is sensitive to harsh conditions. Thus, exposure to organic solvents and ultrasound sonication has to be avoided. Our initial investigations revealed moreover that also freeze-thawing had a detrimental effect on the ligand-receptor affinity (see ESI $\dagger$ ). As shown in a previous study, it is possible to incorporate EGF-conjugated PEG-lipids into pre-formed lipodisks. ${ }^{21}$ In case of small, densely
PEGylated lipodisks, such as those employed in the present study, the post-insertion method results, however, in suboptimally low amounts of incorporated EGF. Thus, the targeting lipodisks used in the studies described in the following were produced by detergent depletion, and, unless otherwise stated, the BioBead-based protocol was employed in order to minimizing radioactive contamination of instruments.

\section{Binding kinetics}

To confirm binding of the EGF-decorated curcumin-containing lipodisks to EGFR-expressing tumour cells, and to retrieve kinetic data concerning the interaction, real-time lipodisk-cell binding experiments were performed. As described in the Experimental section, the lipodisks contained ${ }^{125}$ I-labelled EGF and their interaction with the cells was probed by following the cell-associated radioactivity over time. The results from a typical experiment are displayed in Fig. 4.

Data obtained in the studies show that the EGF-targeting lipodisks bind to the cells in a saturable manner and, importantly, indicate that the disks are capable of selective targeting against the EGFR. Thus, as shown in Fig. 4, the signal due to cell-associated radioactivity is significantly suppressed upon pre-blocking of the cells with free EGF. Additional evidence to support receptor specific binding was collected in a separate experiment in which EGF was instead added subsequent to $24 \mathrm{~h}$ incubation of the cells with the EGF-targeting lipodisks. The results of these studies (see ESI $\dagger$ ) show that the disks, as expected, are displaced from the cells in the presence of excess amounts of free ligand. Notably, the effect of simply removing the incubation medium and replacing it with fresh cell medium was quite different. In this case the cellular retention of the disks was very strong with a non-decreasing signal for several

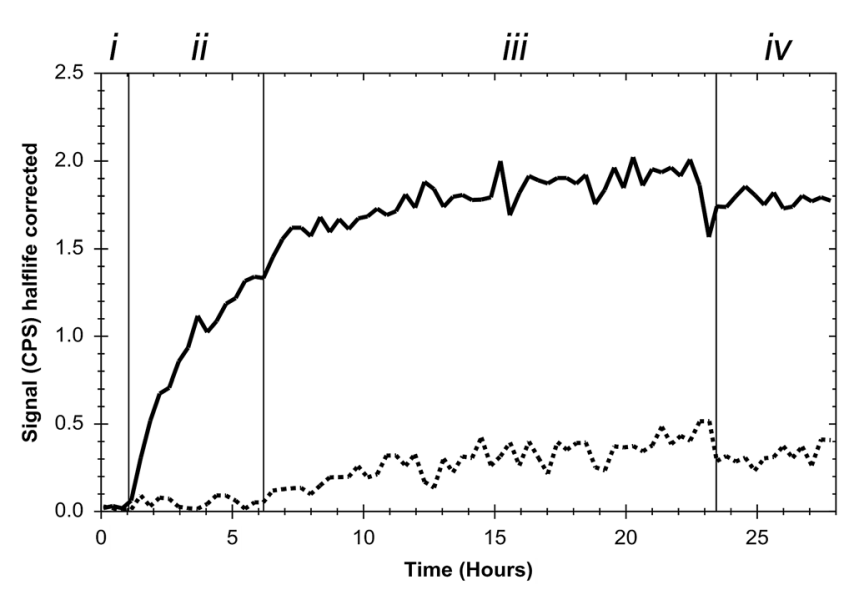

Fig. 4 Real-time analysis of the interaction between EGF-targeting lipodisks (DPPC/cholesterol/curcumin/ ${ }^{125}$ I-EGF-NHS-PEG 3400 -DSPE) and A-431 cells. Section (i): baseline measurement ( $1 \mathrm{~h}$ ) in cell medium. In a parallel blocking experiment (dashed line) free non-labelled EGF was added to a final concentration of $100 \mathrm{nM}$ after $30 \mathrm{~min}$ of the baseline run. Section (ii): medium supplemented with $1 \mu \mathrm{M}$ (total lipid concentration) lipodisks. Section (iii): lipodisk concentration increased to $3 \mu \mathrm{M}$. Section (iv): lipodisk containing medium removed and replaced by $7 \mathrm{~mL}$ of fresh cell medium. To avoid internalization of the receptor the experiments were performed at $4{ }^{\circ} \mathrm{C}$. 
hours (Fig. 4, Section (iv)). The explanation for the strong retention is probably the high avidity design of the targeting lipodisks, rendering them a high apparent affinity for the receptor. The extended retention precluded the calculation of an affinity constant.

It is in this context worth recalling that a small fraction of liposomes was detected by cryo-TEM in the lipodisk samples. In principle, it is possible that these liposomes also present some, but likely very few, EGF-molecules on their surface. Due to the large size, these liposomes would be expected to display much slower binding kinetics than the lipodisks. This, together with the small number of liposomes, makes it reasonable to assume that the signal registered in the binding experiments shown in Fig. 4 originates predominantly from the lipodisks.

Based on the results obtained in the kinetics experiments (see also ESI $\dagger$ ) a lipodisk concentration corresponding to a total lipid concentration of $3 \mu \mathrm{M}$ was used in the binding studies described in the following sections.

\section{Receptor mediated delivery of ${ }^{3} \mathbf{H}$-labelled lipodisks}

The binding of curcumin-containing targeting lipodisks to A431 tumour cells was further investigated in in vitro studies based on the use of ${ }^{3} \mathrm{H}$-DPPC-labelled lipodisks. As shown in Fig. 5, data collected in these studies indicate a time-dependent increase in the cell-associated radioactivity upon incubation of the cells with the targeting lipodisks. Results displayed in the same figure show that pre-incubating the cells with an excess of EGF, and thus blocking the receptor, leads to a clear decrease in the cell-associated radioactivity. At the two later time points $(1 \mathrm{~h}$ and $3 \mathrm{~h}$ ) the reduction was significant $(P<0.004$ at both time points). Data shown in Fig. 5 confirm in addition that replacing the targeting lipodisks with non-targeting lipodisks strongly diminishes the cell-associated ${ }^{3} \mathrm{H}$-radioactivity $(P<0.003$ at all time points).

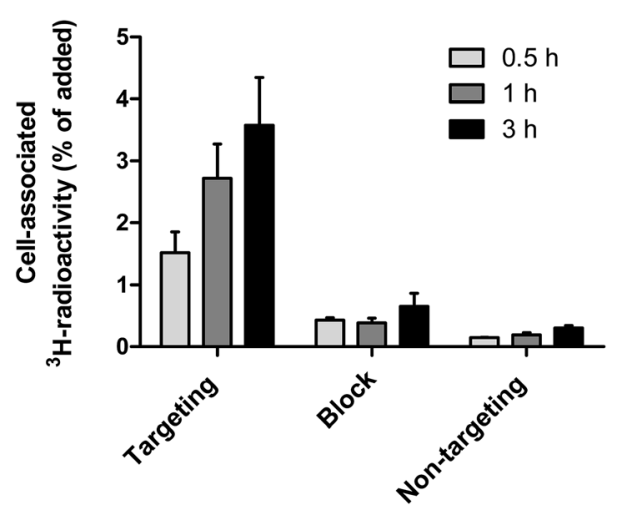

Fig. 5 Cellular binding specificity of curcumin containing targeting lipodisks ( ${ }^{3} \mathrm{H}$-DPPC/cholesterol/curcumin/EGF-NHS-PEG $\left.3400-D S P E\right)$ on A-431 cells. Two groups of cells were incubated with $3 \mu \mathrm{M}$ (total lipid concentration) of the curcumin containing targeting lipodisks at $37^{\circ} \mathrm{C}$. One group of cells was pre-incubated with $100 \mathrm{nM}$ non-labelled free EGF in order to block the EGFRs. A third group of cells was incubated with $3 \mu \mathrm{M}$ of non-targeting curcumin containing lipodisks $\left({ }^{3} \mathrm{H}\right.$-DPPC/cholesterol/curcumin/NHS-PEG $\left.3400-\mathrm{DSPE}\right)$, also at $37^{\circ} \mathrm{C}$. Data are presented as mean \pm range, $n=3$. Error bars might not be seen due to their small size.
The results reported in Fig. 5 verify receptor mediated binding of the curcumin-loaded EGF-targeting lipodisks to the tumour cells.

\section{Cellular internalization of lipodisks}

To investigate if the receptor specific binding of the EGFtargeting lipodisks to the tumour cells results in cellular internalization of the disks, an additional set of binding experiments were carried out. In these studies targeting- and non-targeting ${ }^{3} \mathrm{H}$-DPPC-labelled lipodisks were first incubated with A-431 cells at either 37 or $4{ }^{\circ} \mathrm{C}$. Internalized lipodisks were then detected and distinguished from lipodisks bound to the exterior cell surface by means of an acid-wash assay (see Methods section for details).

The results from these experiments, which are displayed in Fig. 6, suggest that internalization occurs to a large extent in case of EGF-targeting lipodisks incubated with the cells at $37{ }^{\circ} \mathrm{C}$ for $3 \mathrm{~h}$. The observed low levels of surface bound material are expected, given that the EGF receptor, which is internalized along with the lipodisks, does not recycle. ${ }^{35}$ A very different result was obtained for targeting disks incubated at $4{ }^{\circ} \mathrm{C}$. In this case the majority of the cell-associated radioactive material was removed by the acid-wash, indicating that only a small fraction of the disks had been internalized. The internalized fraction may in fact be even smaller than what is suggested in Fig. 6, since it is reasonable to assume that part of the signal originates from incomplete acid washing of the cell surface, i.e., the presence of a so-called acid resistant fraction (valid for all groups in the assay). For cells incubated with non-targeting lipodisks the cell-associated radioactivity was found to be very low in all the investigated fractions. Thus, verifying again that the uptake seen in cells incubated with targeting lipodisks is receptor mediated.

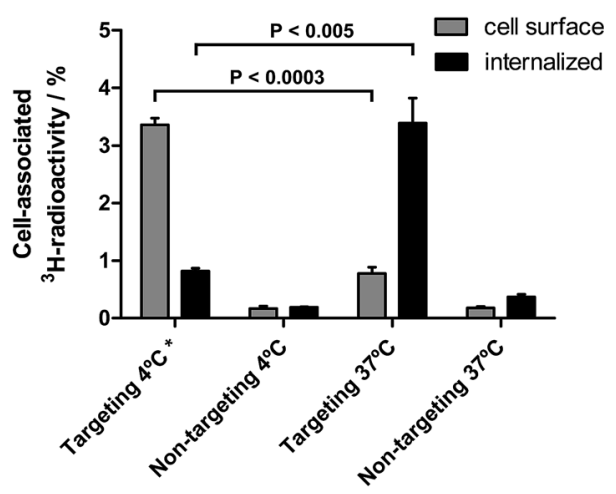

Fig. 6 Acid wash analysis on A-431 cells in vitro. A-431 cells were incubated with either $3 \mu \mathrm{M}$ (total lipid concentration) ${ }^{3} \mathrm{H}$-labelled targeting lipodisks ( ${ }^{3} \mathrm{H}-\mathrm{DPPC} /$ cholesterol/curcumin/EGF-NHS-PEG $3400^{-}$ DSPE) or $3 \mu \mathrm{M}{ }^{3} \mathrm{H}$-labelled non-targeting lipodisks $\left({ }^{3} \mathrm{H}\right.$-DPPC/ cholesterol/curcumin/NHS-PEG 3400 -DSPE) for $3 \mathrm{~h}$. One group/lipodisk type was incubated at either $37^{\circ} \mathrm{C}$ (allowing for EGFR internalization) or $4^{\circ} \mathrm{C}$ (preventing EGFR internalization). The radioactivity that was removed from the cells by treatment of $0.1 \mathrm{M}$ glycine- $\mathrm{HCl}$ solution, $\mathrm{pH} 2.5$, was considered to be bound to the cell surface, and the rest internalized. Data are presented as mean \pm range, $n=3(*: n=2)$. Error bars might not be seen because they are too small. 


\section{Delivery of curcumin}

In an attempt to follow the faith of the lipodisk's therapeutic load, EGF-targeting and non-targeting lipodisks containing ${ }^{3} \mathrm{H}$-labelled curcumin were prepared and investigated in in vitro cell studies. In order to maximise the curcumin load (see Table 1) and achieve sufficient specific radioactivity for the assay, the lipodisks were in this case prepared by means of the SEC-based method. To reduce the non-specific cellular uptake of curcumin, the two groups of ${ }^{3} \mathrm{H}$-curcumin loaded lipodisks and A-431 cells were studied in suspension. The radioactivity associated with the cells after incubation with targeting and non-targeting lipodisks, respectively, for 1,3 or $4 \mathrm{~h}$ is shown in Fig. 7.

At the first time point a significantly higher cellular uptake of ${ }^{3} \mathrm{H}$-curcumin was observed for the group with EGF-targeting lipodisks, as compared to the group with non-targeting lipodisks. Thus, after one hour of incubation the uptake of ${ }^{3} \mathrm{H}$ curcumin was measured to be $3350 \pm 111$ and $2430 \pm 47 \mathrm{cpm}$ for the former and latter group, respectively $(P<0.0043)$. At $3 \mathrm{~h}$ the difference between the groups was reduced, but still significant $(P<0.039)$. At the latest time point $(4 \mathrm{~h})$ the difference between the groups was reduced even further. Part of the reason for the decreasing difference can likely be traced back to a comparably high nonspecific cellular uptake of curcumin. Despite curcumin's low aqueous solubility, a non-negligible fraction of the solubilized drug can be expected to distribute from the disks to the incubation medium. Previous investigations of curcumin loaded unilamellar vesicles composed of 1,2dipalmitoyl-sn-glycero-3-phosphocholine (DSPC) and cholesterol (DSPC : cholesterol in molar ratio 3:2) indicate, for instance, more than $20 \%$ release of encapsulated curcumin after $2 \mathrm{~h}$ incubation in $0.9 \%$ saline at $37{ }^{\circ} \mathrm{C} .{ }^{36}$ Curcumin released into the cell medium will, due to its strong tendency to adsorb to lipid membranes, rapidly transfer to the tumour cells. This promotes further release from the disks, and, as a consequence, the background signal due to nonspecific uptake of curcumin increases over time and may obscure differences in

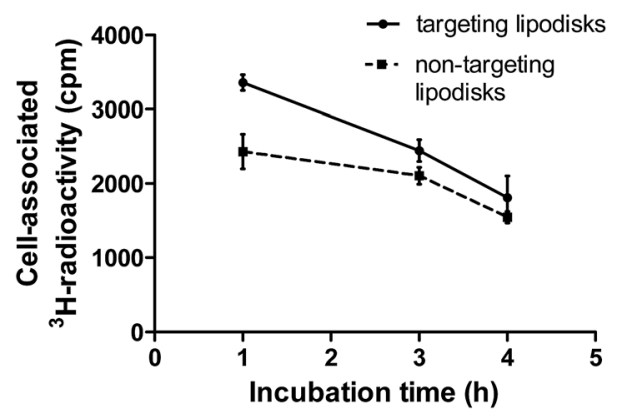

Fig. 7 Receptor specific delivery of ${ }^{3} \mathrm{H}$-labelled curcumin loaded in targeting lipodisks DPPC/cholesterol/ ${ }^{3} \mathrm{H}$-curcumin/EGF-NHS$\mathrm{PEG}_{3400}$-DSPE or non-targeting lipodisks in A-431 cells were studied. A-431 cells were incubated with either $3 \mu \mathrm{M}$ (total lipid concentration) ${ }^{3} \mathrm{H}$-labelled targeting lipodisks $\left({ }^{3} \mathrm{H}\right.$-DPPC/cholesterol/curcumin/EGFNHS-PEG 3400 -DSPE) or $3 \mu \mathrm{M}^{3} \mathrm{H}$-labelled non-targeting lipodisks ( ${ }^{3} \mathrm{H}$ $\mathrm{DPPC} /$ cholesterol/curcumin/NHS-PEG $3400-\mathrm{DSPE}$ ) at $37^{\circ} \mathrm{C}$ for 1,3 or $4 \mathrm{~h}$. Data are presented as mean \pm range, $n=3$ (at $1 \mathrm{~h}$ : $P<0.0043$, at $3 \mathrm{~h}: P<0.039$ and at $4 \mathrm{~h}: P<0.021)$. cellular uptake originating from receptor-mediated curcumin delivery. In vitro measurements of lipodisk-mediated delivery of curcumin are moreover complicated by the fact that curcumin, even in low quantities, can affect the physical properties of cell membranes, which, in turn, may modify the function of embedded membrane proteins. ${ }^{37,38}$ In line with this, recent studies by Starok et al. suggest that curcumin has a rigidifying effect on the membrane of A-431 cells that slows down the receptor diffusion and thereby affects the dimerization that is necessary for receptor internalization. ${ }^{39}$

We have at present no good explanation for why, in case of incubation with both EGF-targeting and non-targeting lipodisks, the absolute signal from the cell-associated ${ }^{3} \mathrm{H}$ curcumin decreases over time. The reduced signal suggests, however, that a significant proportion of the curcumin taken up by the cells is degraded. Curcumin is rapidly degraded in aqueous solution ${ }^{\mathbf{4 0}}$ and our results indicate that also cell membrane bound curcumin may be subject to degradation. Binding of curcumin to lipid membranes is believed to occur in a two-step process where the molecule initially binds to the membrane-water interface and then gradually inserts into the hydrocarbon region of the membrane. ${ }^{41}$ It can be speculated that curcumin is not fully protected from degradation when bound to the membrane-water interface.

\section{Summary and concluding remarks}

The goal of this study was to develop targeting lipodisks with the capacity to selectively deliver poorly water-soluble anticancer agents into tumour cells. To this end we investigated different methods for the production of drug-loaded targetinglipodisks and evaluated the potential of the lipodisks for receptor-mediated drug delivery.

Our results confirm that substantial amounts of the model substance curcumin can be successfully loaded into lipodisks, and show that it is possible to provide the drug-loaded lipodisks with relevant amounts of delicate tumour-targeting agents, such as EGF. Data from our in vitro studies verify moreover that EGF-decorated lipodisks are capable of receptor-specific binding to human A-431 tumour cells, and, importantly, that the binding leads to EGFR-mediated internalization of the disks.

Taken together, the findings reported in the present study point towards targeting lipodisks as promising nanocarriers for specific delivery of poorly soluble anticancer agents to tumour cells.

\section{Acknowledgements}

The authors thank Dr Jonny Eriksson for skilful technical assistance with the cryo-TEM analysis and Dr Hanna Björkelund for technical support with images from the ligand tracer experiments, as well as Dr Malin Morin Zetterberg for help during the lipodisk production. Financial support from the Swedish Cancer Society and the Swedish Research Council is gratefully acknowledged. 


\section{References}

1 Y. Matsumura and H. Maeda, Cancer Res., 1986, 46, 63876392.

2 H. Nakamura, J. Fang and H. Maeda, Expert Opin. Drug Delivery, 2015, 12, 53-64.

3 V. Torchilin, Adv. Drug Delivery Rev., 2011, 63, 131-135.

4 N. Bertrand, J. Wu, X. Xu, N. Kamaly and O. C. Farokhzad, Adv. Drug Delivery Rev., 2014, 2-25.

5 N. R. Patel, B. S. Pattni, A. H. Abouzeid and V. P. Torchilin, Adv. Drug Delivery Rev., 2013, 65, 1748-1762.

6 A. Z. Wang, R. Langer and O. C. Farokhzad, Annu. Rev. Med., 2012, 63, 185-198.

7 M. Narvekar, H. Y. Xue, J. Y. Eoh and H. L. Wong, AAPS PharmSciTech, 2014, 15, 822-833.

8 P. Yingchoncharoen, D. S. Kalinowski and D. R. Richardson, Pharmacol. Rev., 2016, 68, 701-787.

9 T. M. Allen and P. R. Cullis, Adv. Drug Delivery Rev., 2013, 65, 36-48.

10 N. R. Stone, T. Bicanic, R. Salim and W. Hope, Drugs, 2016, 76, 485-500.

11 S. Koudelka and J. Turánek, J. Controlled Release, 2012, 163, 322-334.

12 G. T. Noble, J. F. Stefanick, J. D. Ashley, T. Kiziltepe and B. Bilgicer, Trends Biotechnol., 2014, 32, 32-45.

13 N. P. Truong, M. R. Whittaker, C. W. Mak and T. P. Davis, Expert Opin. Drug Delivery, 2015, 12, 129-142.

14 K. Edwards, M. Johnsson, G. Karlsson and M. Silvander, Biophys. J., 1997, 73, 258-266.

15 E. Johansson, A. Lundquist, S. S. Zuo and K. Edwards, Biochim. Biophys. Acta, 2007, 1768, 1518-1525.

16 E. Meiby, M. M. Zetterberg, S. Ohlson, V. A. Hernandez and K. Edwards, Anal. Bioanal. Chem., 2013, 405, 4859-4869.

17 M. D. Duong-Thi, M. Bergstrom, K. Edwards, J. Eriksson, S. Ohlson, J. T. Ying, J. Torres and V. Agmo Hernandez, Analyst, 2016, 141, 981-988.

18 W. P. Zhang, J. Sun, Y. Liu, M. Y. Tao, X. Y. Ai, X. N. Su, C. F. Cai, Y. L. Tang, Z. Feng, X. D. Yan, G. L. Chen and Z. G. He, Mol. Pharmaceutics, 2014, 11, 3279-3290.

19 M. M. Zetterberg, K. Reijmar, M. Pranting, A. Engstrom, D. I. Andersson and K. Edwards, J. Controlled Release, 2011, 156, 323-328.

20 J. Gao, C. Xie, M. Zhang, X. Wei, Z. Yan, Y. Ren, M. Ying and W. Lu, Nanoscale, 2016, 8, 7209-7216.

21 M. M. Zetterberg, S. Ahlgren, V. Agmo Hernández, N. Parveen and K. Edwards, J. Colloid Interface Sci., 2016, 484, 86-96.
22 E. B. Kullberg, N. Bergstrand, J. Carlsson, K. Edwards, M. Johnsson, S. Sjöberg and L. Gedda, Bioconjugate Chem., 2002, 13, 737-743.

23 E. B. Kullberg, Q. Wei, J. Capala, V. Giusti, P.-U. Malmström and L. Gedda, Int. J. Radiat. Biol., 2005, 81, 621-629.

24 M. Almgren, K. Edwards and G. Karlsson, Colloids Surf., A, 2000, 174, 3-21.

25 J. V. Paraskova, E. Rydin and P. J. R. Sjöberg, Talanta, 2013, 115, 336-341.

26 O. Naksuriya, S. Okonogi, R. M. Schiffelers and W. E. Hennink, Biomaterials, 2014, 35, 3365-3383.

27 M. Z. Ahmad, S. A. Alkahtani, S. Akhter, F. J. Ahmad, J. Ahmad, M. S. Akhtar, N. Mohsin and B. A. Abdel-Wahab, J. Drug Targeting, 2016, 24, 273-293.

28 M. K. Shanmugan, G. Rane, M. M. Kanchi, F. Arfuso, A. Chinnathambi, M. E. Zayed, S. A. Alharbi, B. K. Tan, A. P. Kumar and G. Sethi, Molecules, 2015, 20, 2728-2769.

29 C. Mohanty, M. Das and S. K. Sahoo, Expert Opin. Drug Delivery, 2012, 9, 1347-1364.

30 M. C. Sandström, E. Johansson and K. Edwards, Biophys. Chem., 2008, 132, 97-103.

31 M. Ghosh, A. T. K. Singh, W. Xu, T. Sulchek, L. Gordon and R. O. Ryan, Nanomedicine, 2011, 7, 162-167.

32 S. Sebastian, J. Settleman, S. J. Reshkin, A. Azzariti, A. Bellizzi and A. Paradiso, Biochim. Biophys. Acta, 2006, 1766, 120-139.

33 C. Marmot, D. C. Drummond, C. O. Noble, V. Kallab, Z. Gou, K. Hong, D. B. Kirpotin and J. W. Park, Cancer Res., 2005, 65, 11631-11638.

34 C. Marmot, R. Ritschard, A. Wicki, W. Küng, J. Schuller, R. Herrmann and C. Rochkitz, J. Drug Targeting, 2012, 20, 422-432.

35 S. A. Prigent and N. R. Lemoine, Prog. Growth Factor Res., 1992, 4, 1-24.

36 S. L. Gosangari and K. L. Watkin, Pharm. Dev. Technol., 2012, 17, 103-109.

$37 \mathrm{H}$. I. Ingolfsson, R. E. Koeppe and O. S. Andersen, Biochemistry, 2007, 46, 10384-10391.

38 W.-C. Hung, F.-Y. Chen, C.-C. Lee, Y. Sun, M.-T. Lee and H. W. Huang, Biophys. J., 2008, 94, 4331-4338.

39 M. Starok, P. Preira, M. Vayssade, K. Haupt, L. Salomé and C. Rossi, Biomacromolecules, 2015, 16, 1634-1642.

40 Y. J. Wang, M. H. Pan, A. L. Cheng, L. I. Lin, Y. S. Ho, C. Y. Hsieh and J. K. Lin, J. Pharm. Biomed. Anal., 1997, 15, 1867-1876.

41 Y. Sun, C.-C. Lee, W.-C. Hung, F.-Y. Chen, M.-T. Lee and H. W. Huang, Biophys. J., 2008, 95, 2318-2324. 